\title{
Sandwich Structure Composite with Expandable Graphite Filled or Coated: Evaluation of Flame Retardancy and Mechanical Performances
}

\author{
Chenkai Zhu, Jingjing Li, Fanhao Ji, Xiaosu Yi, Chris Rudd, Xiaoling Liu* \\ University of Nottingham Ningbo China, Ningbo, China \\ Email: *Xiaoling.Liu@nottin gham.edu.cn
}

How to cite this paper: Zhu, C.K., Li, J.J., Ji, F.H., Yi, X.S., Rudd, C. and Liu, X.L. (2019) Sandwich Structure Composite with Expandable Graphite Filled or Coated: Evaluation of Flame Retardancy and Mechanical Performances. Open Journal of Safety Science and Technology, 9, 7-21. https://doi.org/10.4236/ojsst.2019.91002

Received: January 15, 2019

Accepted: February 11, 2019

Published: February 14, 2019

Copyright $\odot 2019$ by author(s) and Scientific Research Publishing Inc. This work is licensed under the Creative Commons Attribution International License (CC BY 4.0).

http://creativecommons.org/licenses/by/4.0/

(c) (i) Open Access

\begin{abstract}
Sandwich composites are increasingly used in high-performance application due to their high specific stiffness, strength and thermal insulation. The sandwich composites were developed using honeycomb and carbon fibre reinforced composite face sheet in this study. Expandable graphite (EG) weighting $5 \mathrm{wt} \%$ and $10 \mathrm{wt} \%$ were filled in honeycomb or coated on face sheet to improve the fireproof performance. The vertical burning test, cone calorimetry test, thermal insulation analysis, scanning electron microscopy and mechanical test were taken into account. With the increase of EG in the sandwich composites, a significant improvement on flame retardancy with better thermal insulation, lower values of peak heat release rate and MAHRE were confirmed for sandwich composite with EG both coated and filled. In addition, the sandwich with EG coated on face sheet presented better fire resistivity and thermal insulation properties when compared to that with EG filled in honeycomb. However, more total smoke release was also observed for EG coated composites due to partial combustion of resin within sufficient heat and oxygen. Furthermore, no significant effect on the mechanical properties of composites was confirmed from both fireproof approaches.
\end{abstract}

\section{Keywords}

Expandable Graphite, Sandwich, Honeycomb, Fire Resistance, Mechanical Performance

\section{Introduction}

Composite materials are one of the lightweight materials for transportation in- 
dustries (aviation, marine, railway vehicles) and construction (such as bridges, wind turbine blade) due to their excellent mechanical performance, thermal insulation characteristics, fatigue and corrosion resistance [1]. Normally, for load-bearing application, an increase inmoment of inertia of the component area is required to ensure mechanical stability. As such, sandwich structures of thin composite face sheets with thick and low density core material are preferred [2] [3].

However, their poor fire resistance is the critical problem of the sandwich structures in engineering applications [4]. Most of the materials that are used for the polymer matrix of the face sheets (epoxy, vinyl ester, polyester resin) and the core materials (polymeric foam, balsa wood, honeycomb) are flammable [5]. In the presence of fire or high temperature, the sandwich structures will decompose, ignite and burn, releasing heat, smoke, toxic gases, which can cause severe injury and death [6] [7]. Therefore, to use in structural applications, the fire resistance of the sandwich structures should be improved.

A common strategy to improve the flame retardant performance of sandwich composite involves the modification of the matrix via the addition of micro-sized flame retardant agents. Several studies in the literature have successfully demonstrated improvement in fire reaction properties of composites inclusion of flame retardant additives [8] [9] [10] [11]. However, the flame retardant performance of composites is achieved at elevated fire retardant loading concentrations, while high fire retardant loadings lead to the degradation in mechanical properties of flame retarded polymer composites [12] [13]. To circumvent this issue, flame retardant strategies should preclude the inclusion of flame retardant additives in the polymer composite matrix.

In this case, the other available strategies developed is the application of flame retardants protection layer such as insulative materials or flame retardant coatings on heat-exposed surfaces of sandwich composite structures, or the application of flame retardant filler in the honeycomb or foam core to improve the thermal insulation performance.

Expandable graphite has been used in numerous applications of fire safety, especially thermal insulators and intumescent flame retardant for polymer composite [14] [15] [16]. Expandable graphite (EG) is equivalent to a staged version of a graphite-sulfuric acid salt; i.e. the graphene layers all remain intact while bisulfate ions are intercalated between these layers [17]. The key property of expandable graphite is the tendency to exfoliate when heated at high temperatures beyond a characteristic expansion onset temperature [18]. It expands rapidly in a worm-like manner to form vermicular graphite with a low density. Kahlili et al. [19] who have worked on EG for polymer composite, and compared flame retardant properties of the composite with a surface coating and matrix filling, found that the composites both coated or filled with EG could provide a significant improvement on flame retardant performance.

However, even though a lot of research about EG for flame retardant composite [14] [17] [20] [21] [22] [23] have been reported in the literature, not too 
many studies about sandwich composite using expandable graphite, especially using the EG for thermal insulation analysis. Additionally, it should be interesting to investigate the effect of EG on the mechanical properties of sandwich,

Therefore, the aim of this paper is to investigate the effect of EG on the flame retardant performance and thermal insulation properties of the sandwich composite. Two fireproof approaches, EG coated on the face sheet and EG filled in the core-honeycomb of sandwich, were taken into account in this study. The vertical burning test, cone calorimetry test and thermal insulation properties of the composite with both approaches were analysed for comparison.

\section{Materials and Methods}

\subsection{Design and Manufacture of Sandwich Composites}

The sandwich composites in this study were designed as Figure 1, which were produced from the carbon fibre/epoxy resin prepreg containing $49 \mathrm{wf} \%$ resin with an areal density of $345 \mathrm{~g} / \mathrm{m}^{2}$ (AVIC Composite, China). The Nomex honeycomb of an areal density of $240 / \mathrm{m}^{2}$ was selected for core material (NHC-1, AVIC Composite, China). The manufacturing process was vacuum bagging at curing temperature. The skin with three layers prepreg was placed on the top and bottom of honeycomb, then covered by vacuum bag with vacuum at 1 bar and placed into the oven for 2 hours curing at $120^{\circ} \mathrm{C}$.

As can be seen from Table 1, there are five sample groups in this study. For flame retardant sandwich composites C-5 and C-10, the expandable graphite particles $(180 \mu \mathrm{m}$ mesh size and expansion ratio of 100:1) were sprayed on the face of skin and adhered by resin of prepreg before the vacuum bagging process, then vacuumed with 1 bar as well, and moved into the oven for curing at the same temperature. Additionally, the F-5 and F-10 composites where the expandable graphite was filled in the honeycomb with even distribution.

\subsection{Vertical Bunsen Test}

Vertical Bunsen testing was conducted to investigate the flame resistance of sandwich composites. Testing experiments were set up according to Federal Aviation Regulation (FAR) 25.853 standard of $60 \mathrm{~s}$ Vertical Bunsen burner testing specifications. The flame of methane gas was adjusted to the reach height of $38 \mathrm{~mm}$ flame above the top level of the burner barrel, which was $19 \mathrm{~m}$ below the edge of the specimen, and the flame was positioned under the centre of the specimen. There were three specimens for each group with a dimension of $305 \mathrm{~mm}$ (Length) $\times 75 \mathrm{~mm}$ (width) $\times 7.8 \mathrm{~mm}$ (thickness) individually hanged upright with the aid of a retort stand and clamp, and tested accordingly using burner (TESTech Instrument Technologies Co., Ltd, China). The burn length, drip flame time, flame time were studied and recorded.

Due to the sandwich structure and different materials on skin and core, the burning length of skin and core was both investigated, as such the cross-section of the sandwich composite was cut for measurement of the burn length of the sandwich structure. 


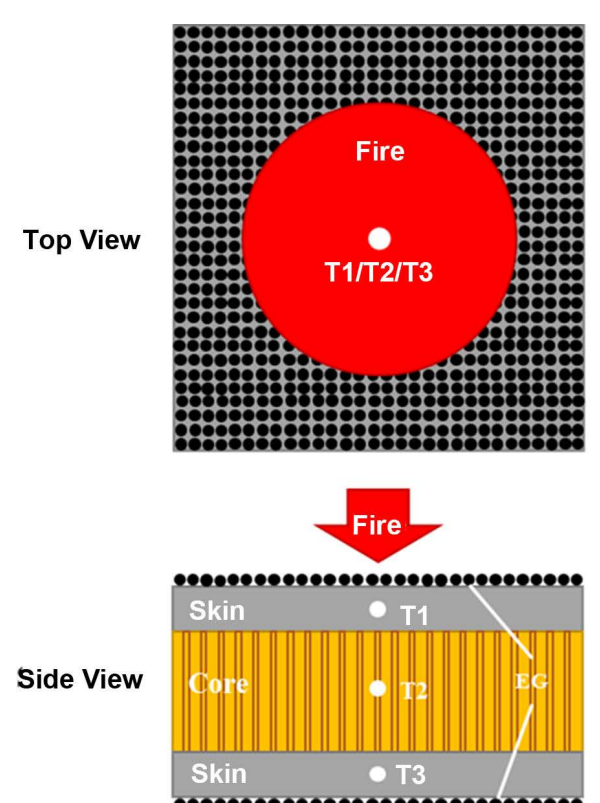

(a)
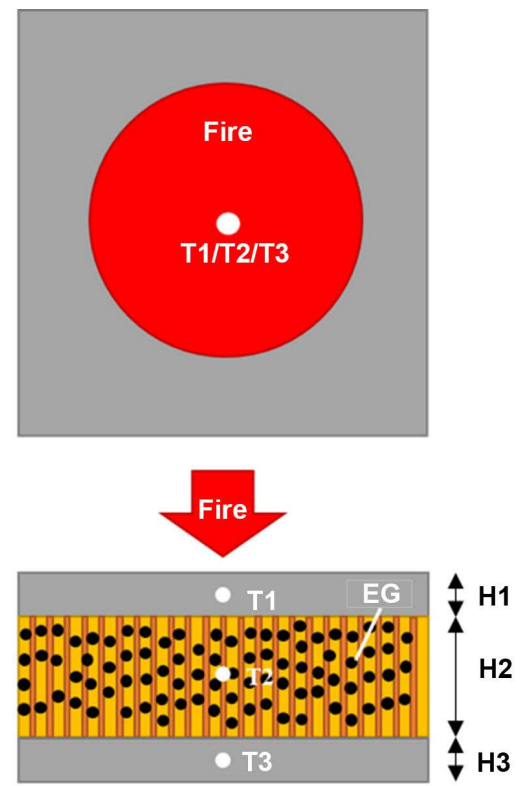

(b)

Figure 1. The illustration showing the sandwich structure and location thermocouples inserted across the thickness of composite: (a) C-5 and C-10 sandwich composites; (b) F-5 and F-10 sandwich composite.

Table 1. The detail composition and dimension of the sandwich composite in this study.

\begin{tabular}{ccccccccc}
\hline \multirow{2}{*}{$\begin{array}{c}\text { Sample } \\
\text { codes }\end{array}$} & \multicolumn{4}{c}{ Composite composition (wt\%) } & \multicolumn{4}{c}{ Thickness (mm) } \\
\cline { 2 - 9 } & CF & Resin & Honeycomb & EG Filling & EG Coating & H1 & H2 & H3 \\
\hline Control & 46 & 44 & 10 & $/$ & $/$ & 1.34 & 5.15 & 1.33 \\
F-5 & 43 & 42 & 10 & 5 & $/$ & 1.32 & 5.17 & 1.34 \\
F-10 & 41 & 40 & 9 & 10 & $/$ & 1.35 & 5.15 & 1.33 \\
C-5 & 43 & 42 & 10 & $/$ & 5 & 1.51 & 5.18 & 1.53 \\
C-10 & 41 & 40 & 9 & $/$ & 10 & 1.61 & 5.14 & 1.59 \\
\hline
\end{tabular}

\subsection{Cone Calorimetry Test}

The cone calorimeter tests were conducted on a cone calorimeter (Fire Testing Technology Ltd., UK) with sample dimension of $100 \mathrm{~mm} \times 100 \mathrm{~mm} \times$ nominal thickness and subjected to one-sided radiant heating according to the ISO5660-1 at the heat flow of $35 \mathrm{~kW} / \mathrm{m}^{2}$. The heat exposed surfaces of the test specimens were placed $25 \mathrm{~mm}$ away from the cone heater. Cone calorimeter parameters including the time to ignition (TTI), time to flame out (TTFO), peak heat release rate (PHRR), total heat release (THR), total smoke release (TSR) and maximum average heat rate emission (MAHRE) were measured.

\subsection{Thermal Insulation Property}

The temperature on the fire retardant sandwich surface and the honeycomb were measured to estimate the thermal insulation performance. Two K-type thermocouples was attached on the surface of the sandwich specimen (T1) ex- 
posed to the flame and the opposite side surface (T3), respectively, and one was inserted into the honeycomb (T2) which had been marked in Figure 1. The surface of the sandwich was exposed to alcohol burner with a flame temperature of $500^{\circ} \mathrm{C}$ for $1000 \mathrm{~s}$, the time to thermal equilibrium temperature for each side and honeycomb was recorded.

\subsection{Flexural Properties Analysis}

To analyse the mechanical properties behaviour of the sandwich composite, the specimens were subjected to flexural test by three-point bending test through a 50KN UTM (MTS E42) following the ASTM C393. The specimens were prepared with $200 \mathrm{~mm}$ length, $75 \mathrm{~mm}$ width, and a span of $150 \mathrm{~mm}$ with the rate of loading was $2 \mathrm{~mm} / \mathrm{min}$.

\subsection{Microstructure Observation}

The micromorphology images of the char residues after cone calorimeter test were observed on a scanning electron microscope (SEM, Zeiss ${ }^{\oplus}$, Germany) at a $10 \mathrm{KV}$ voltage after sputtered with $5 \mathrm{~nm}$ gold using vacuum film deposition system (EM SCD500, Leica ${ }^{\circledR}$, Germany).

\subsection{Statistical Analysis}

Statistical analysis was performed with GraphPad Prism (Version 7.00, GraphPad Software, San Diego, CA, USA) with unpaired t-tests. Confidence level was 95\%.

\section{Results and Discussion}

\subsection{Vertical Bunsen Burner Test}

Vertical Bunsen Burner Test is a traditional method to investigate the flammability of materials. The results in Table 2 showed that the flammability of sandwich was reduced significantly with the incorporation of expandable graphite (EG) on the surface or into the honeycomb of the sandwich. The Flame Time of the sandwich was observed to decrease from $54 \pm 5 \mathrm{~s}$ to $45 \pm 2 \mathrm{~s}$ with the addition of EG into honeycomb from $0 \mathrm{wt} \%$ to $10 \mathrm{wt} \%$. According to Figure 2 and Table 2, a decrease of Burn Length was also observed for sandwich composites with EG filling, and Burn Length of honeycomb was significantly lower than Skin for F-5 and F-10 sandwich composite respectively. This was attributed to the EG in the honeycomb rather than on the surface, the Skin-laminate with rich resin was ignited and burning with the fire whilst the EG was able to expand and form the worm-like char filling the gap of honeycomb, becoming the thermal barrier to prevent flame spreading along the Core.

With the same mass fraction of EG coated on the face sheet of sandwich composites, C-5 and C-10 presented lower Flame Time and Burn Length, when compared with EG filled sandwich (F-5 and F-10). The Flame Time was decreased to $30 \pm 2 \mathrm{~s}$ and $6 \pm 2 \mathrm{~s}$ for $5 \mathrm{wt} \%$ and $10 \mathrm{wt} \%$, respectively. The first 


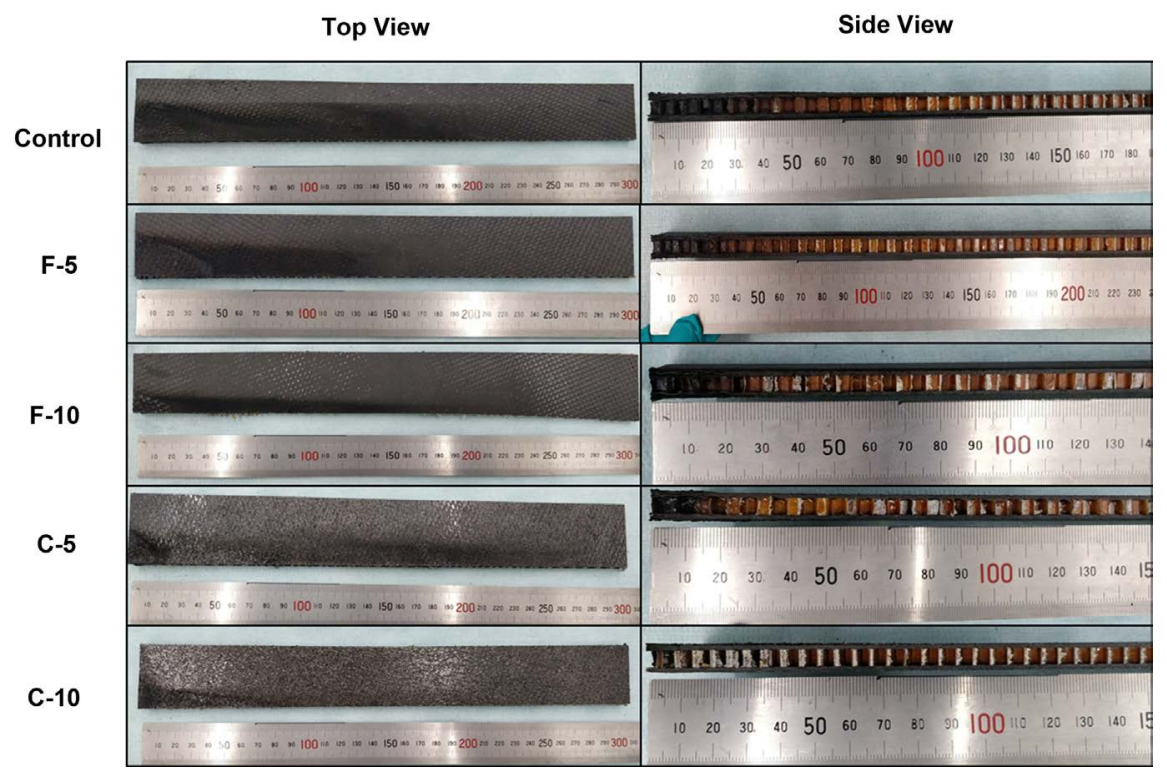

Figure 2. The samples burned by vertical Bunsen burner test.

Table 2. The Flame Time, Drip Flame Time and Burn Length of specimens during the vertical Burning test.

\begin{tabular}{ccccc}
\hline \multirow{2}{*}{ Sample Code } & Flame Time (s) & $\begin{array}{c}\text { Drip Flame } \\
\text { Time }(\mathrm{s})\end{array}$ & \multicolumn{2}{c}{ Burn Length (mm) } \\
\cline { 4 - 5 } & & 0 & Skin-Laminates & Core-Honeycomb \\
\hline Control & $54 \pm 5$ & 0 & $45 \pm 2$ & $40 \pm 2$ \\
F-5 & $49 \pm 3$ & 0 & $35 \pm 2$ & $35 \pm 2$ \\
F-10 & $45 \pm 2$ & 0 & $25 \pm 3$ & $15 \pm 1$ \\
C-5 & $30 \pm 2$ & 0 & $8 \pm 1$ & $15 \pm 2$ \\
C-10 & $6 \pm 2$ & & & $8 \pm 1$ \\
\hline
\end{tabular}

reason could be the EG on the face sheet of sandwich (Skin-Laminate) exposed to fire was fully expanded immediately, the formed thermal barrier on the composite surface could retard the flame spreading on the composite surface [19].

\subsection{Cone Calorimetry Test}

The effectiveness of fire-proofing approach filling the Expandable Graphite (EG) into the Honeycomb of sandwich or coat on the face sheet of the sandwich composite was evaluated. The HRR-time curve for sandwich composites were shown in Figure 3, and the detail data were recorded in Table 3. It was suggested that the fire reaction behaviour of the sandwich was significantly improved via filling the EG into a honeycomb of composite or coating EG on the face sheet.

Considering the first $100 \mathrm{~s}$ of thermal exposure, the reaction behaviour of composite with EG filled (F-5 and F-10) were similar to that of Control. The HRR of Control, F-5 and F-10 composites increased rapidly following self-sustained ignition, reaching the peak value of $322 \pm 12,293 \pm 11,260 \pm 9 \mathrm{KW} / \mathrm{m}^{2}$, 


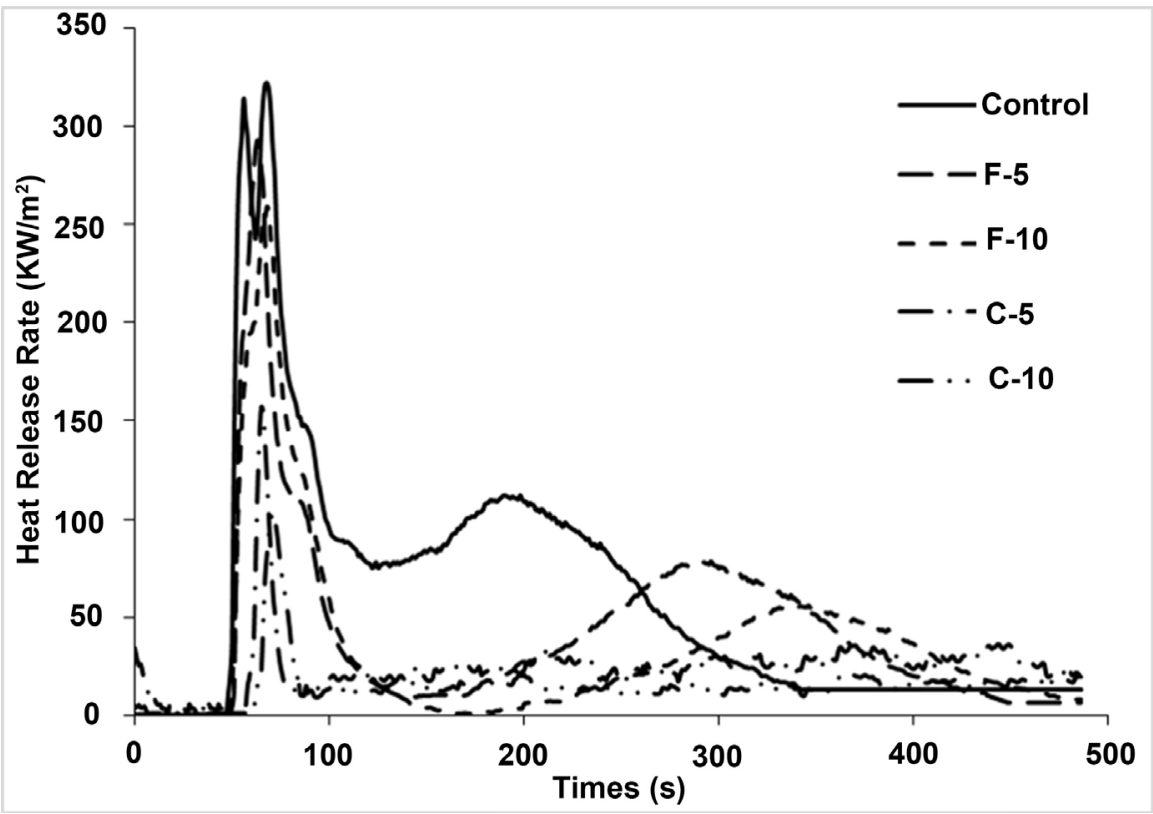

Figure 3. The heat release rate vs time curves at $35 \mathrm{~kW} / \mathrm{m}^{2}$ of the intumescent coated samples before and after water-soak.

Table 3. Cone calorimetric data for the control and all specimens at $35 \mathrm{~kW} / \mathrm{m}^{2}$ heat fluxes with an ignition source.

\begin{tabular}{ccccccc}
\hline \multirow{2}{*}{$\begin{array}{c}\text { Sample } \\
\text { Code }\end{array}$} & $\begin{array}{c}\text { Time to } \\
\text { Ignition } \\
(\mathrm{s})\end{array}$ & $\begin{array}{c}\text { Time to } \\
\text { Flame Out } \\
(\mathrm{s})\end{array}$ & $\begin{array}{c}\text { Peak HRR } \\
\left(\mathrm{KW} / \mathrm{m}^{2}\right)\end{array}$ & $\begin{array}{c}\text { Total Heat } \\
\text { Release } \\
\left(\mathrm{MJ} / \mathrm{m}^{2}\right)\end{array}$ & $\begin{array}{c}\text { Total Smoke } \\
\text { Release }\left(\mathrm{m}^{2} / \mathrm{m}^{2}\right)\end{array}$ & $\begin{array}{c}\text { MAHRE } \\
\left(\mathrm{KW} / \mathrm{m}^{2}\right)\end{array}$ \\
\hline Control & $48 \pm 2$ & $137 \pm 2$ & $322 \pm 12$ & $27 \pm 5$ & $620 \pm 10$ & $103 \pm 5$ \\
F-5 & $47 \pm 2$ & $166 \pm 2$ & $293 \pm 11$ & $21 \pm 4$ & $622 \pm 11$ & $77 \pm 6$ \\
F-10 & $49 \pm 1$ & $155 \pm 2$ & $260 \pm 9$ & $17 \pm 2$ & $354 \pm 8$ & $66 \pm 7$ \\
C-5 & $60 \pm 2$ & $85 \pm 2$ & $157 \pm 8$ & $9 \pm 1$ & $1000 \pm 12$ & $45 \pm 4$ \\
C-10 & $65 \pm 1$ & $90 \pm 2$ & $103 \pm 9$ & $7 \pm 1$ & $838 \pm 8$ & $33 \pm 5$ \\
\hline
\end{tabular}

respectively. After $100 \mathrm{~s}$, another HRR peaks were also observed at $197 \mathrm{~s}, 290 \mathrm{~s}$ and $334 \mathrm{~s}$, with the peak values of $120 \pm 6,78 \pm 5$ and $61 \pm 8 \mathrm{KW} / \mathrm{m}^{2}$, respectively. The behaviour of the second HRR peak was due to the burning of the back face sheet of sandwich composite. With the filling of EG from $0 \mathrm{wt} \%$ to $10 \mathrm{wt} \%$, more char formed in the honeycomb to be the thermal barrier retard the fire and heat burning through the honeycomb and transfer into the back face sheet, as such $50 \%$ decrease of the second peak of HRR could be observed by $10 \mathrm{wt} \%$ EG filled (F-10) composite.

On the other hand, the HRR value of C-5 and C-10 composites with EG coated was found to increase slowly following ignition which was out in $100 \mathrm{~s}$, resulting in lower PHRR value when compared to other composite groups (Control, F-5 and F-10). It was also attributed to the dense char layer formed from the expanded EG (Shown in Figure 4) provided a thermal-physical barrier 


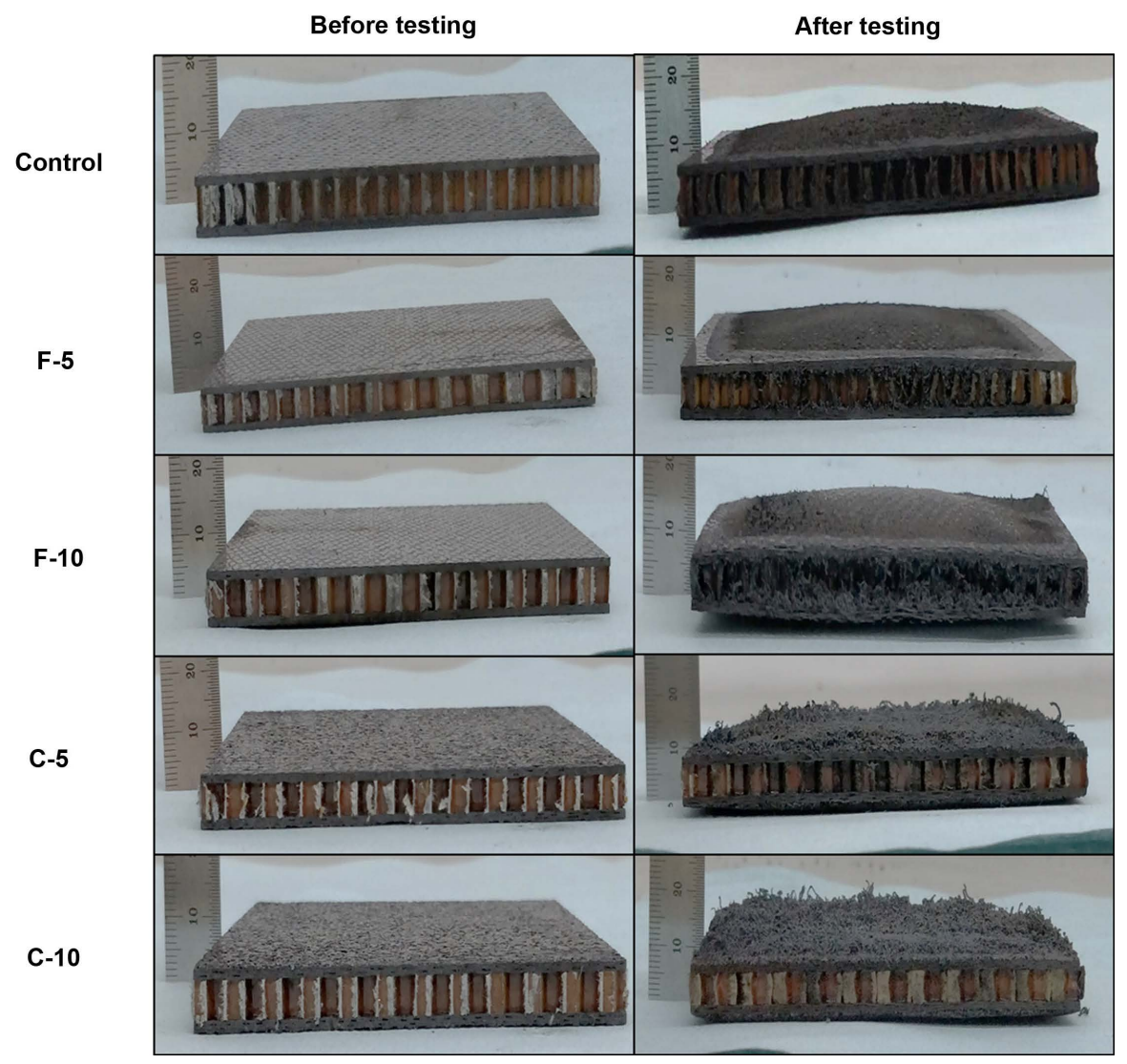

Figure 4. The image of control and all specimens with EG after cone calorimetry test.

that prevented heat conduction and oxygen diffusion to the receding pyrolysis zone.

According to the data in Table 3, the Total Heat Release (THR) value for sandwich composite was reduced from $27 \pm 5$ to $17 \pm 2 \mathrm{MJ} / \mathrm{m}^{2}$ with $10 \mathrm{wt} \%$ EG filled, whilst that reduced to $7 \pm 1 \mathrm{MJ} / \mathrm{m}^{2}$ with $10 \mathrm{wt} \%$ EG coated. In addition, a reduction of Maximum Average Heat Rate Emission profiles (MAHRE) with an addition of EG was observed for sandwich composite. MAHRE value of F-Composite was reduced from $103 \pm 5 \mathrm{KW} / \mathrm{m}^{2}$ for Control to $77 \pm 6$ and $66 \pm 7 \mathrm{KW} / \mathrm{m}^{2}$ for F-5 and F-10 composite, respectively; while $45 \pm 4$ and $33 \pm 5 \mathrm{KW} / \mathrm{m}^{2}$ for C-5 and C-10 was observed.

On the other hand, the Total Smoke Release (TSR) for both fireproof approaches showed interesting behaviours. The TSR value of F-Composite was found to decrease from $620 \pm 10$ (control) to $354 \pm 8 \mathrm{~m}^{2} / \mathrm{m}^{2}$ (F-10), whereas that of the C-Composite with lower PHRR value showed $1000 \pm 12$ and $838 \pm$ $8 \mathrm{~m}^{2} / \mathrm{m}^{2}$ for C-5 and C-10, respectively. This could be attributed to the expanded EG on the face sheet, where the pyrolysis of resin under the fire was retarded with self-extinguishing. Due to the partial combustion without enough heat and oxygen, more unburnt organic particles and gas could release into the air and increase the TSR value.

The flame retardant mechanism of expandable graphite could be confirmed 
via observation of expandable graphite (EG) before and after Cone Calorimetry test. The micrographs of EG were shown in Figure 5. Normally, the EG exfoliation initialled when heated over $200^{\circ} \mathrm{C}$ where the most of intercalating substances degraded and form gases escaped from the interlayer of EG resulting in expanding the graphite with a porous structure. As shown in Figure 5, the virgin EG received from the vendor was in the form of platelet with a diameter range of 210 - $505 \mu \mathrm{m}$. After undergoing the thermal conditions caused by Cone Calorimetry Test, the EG expanded along the z-axis of EG and transformed to be vermicular structure, as such the similar diameter range to the virgin EG was observed for expanded graphite. Therefore, it was indicated that the EG filled in the honeycomb or coated on the face sheet could expand to form worm-like porous char and cross combine to be the dense char layer, which can prevent the fire and heat diffusion and reduce the heat release.

\subsection{Thermal Insulation Test}

In this paper, temperature-time profiles were collected at locations across the thickness of sandwich composites during the thermal insulation test. The temperature-time data at the front surface sheet of sandwich exposed to flame (T1), the honeycomb centre of sandwich (T2) and the back face sheet of the sandwich (T3) for all sandwich composites are shown in Figure 6. The value of T1, T2 and T3 at steady-status, and the time to reach the steady-status were shown in Figure 7.

For T1 temperature of all composite, no significant difference was observed, while the $\mathrm{T} 1$ of steady-state $\left(\mathrm{T} 1_{\mathrm{SS}}\right)$ was recorded at $\$ \$ 00^{\circ} \mathrm{C}$. However, referred to Figure 7, the C-5 and C-10 composite with EG coating cost $\$ 00 \mathrm{~s}$ to reach the $\mathrm{T}_{\mathrm{SS}}$, is much longer than that for Control, F-5 and F-10 composite. It was also attributed to the EG expanded on the surface of the face sheet exposed to fire; as such the heat conduction was retarded by the char layer, resulting in a delay of reaching steady thermal status.

For F-Composites with EG filling, the steady-status temperature of T2 (T2 $\left.{ }_{\mathrm{SS}}\right)$ was observed to decrease from $\$ 00^{\circ} \mathrm{C}$ (Control) to $\$ 06^{\circ} \mathrm{C}(\mathrm{F}-5)$ and $\varangle 688^{\circ} \mathrm{C}$ (F-10), due to the expanded EG in the honeycomb forming the thermal barrier region in the core of sandwich composite. Moreover, the $\mathrm{T} 3_{\mathrm{SS}}$ of F-Composite

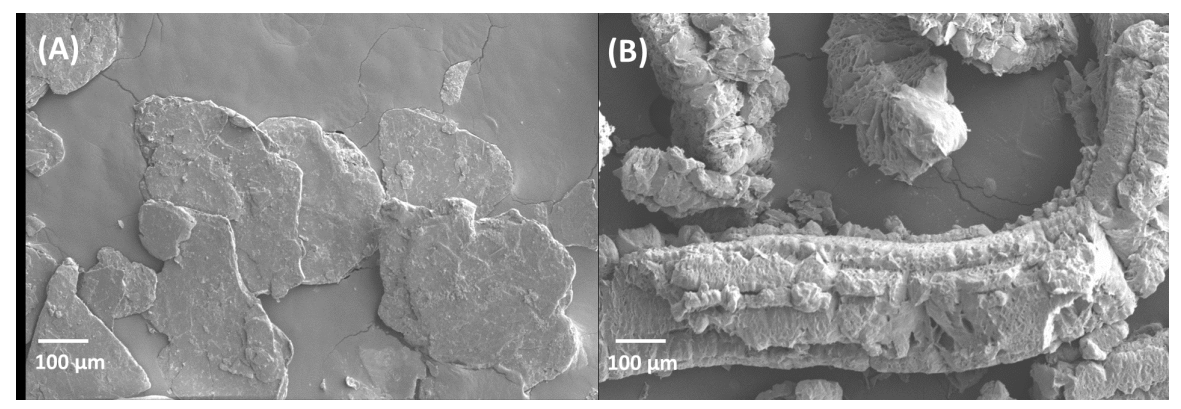

Figure 5. SEM Image of Expandable graphite (A) before Cone calorimetry test (B) after Cone calorimetry test. 

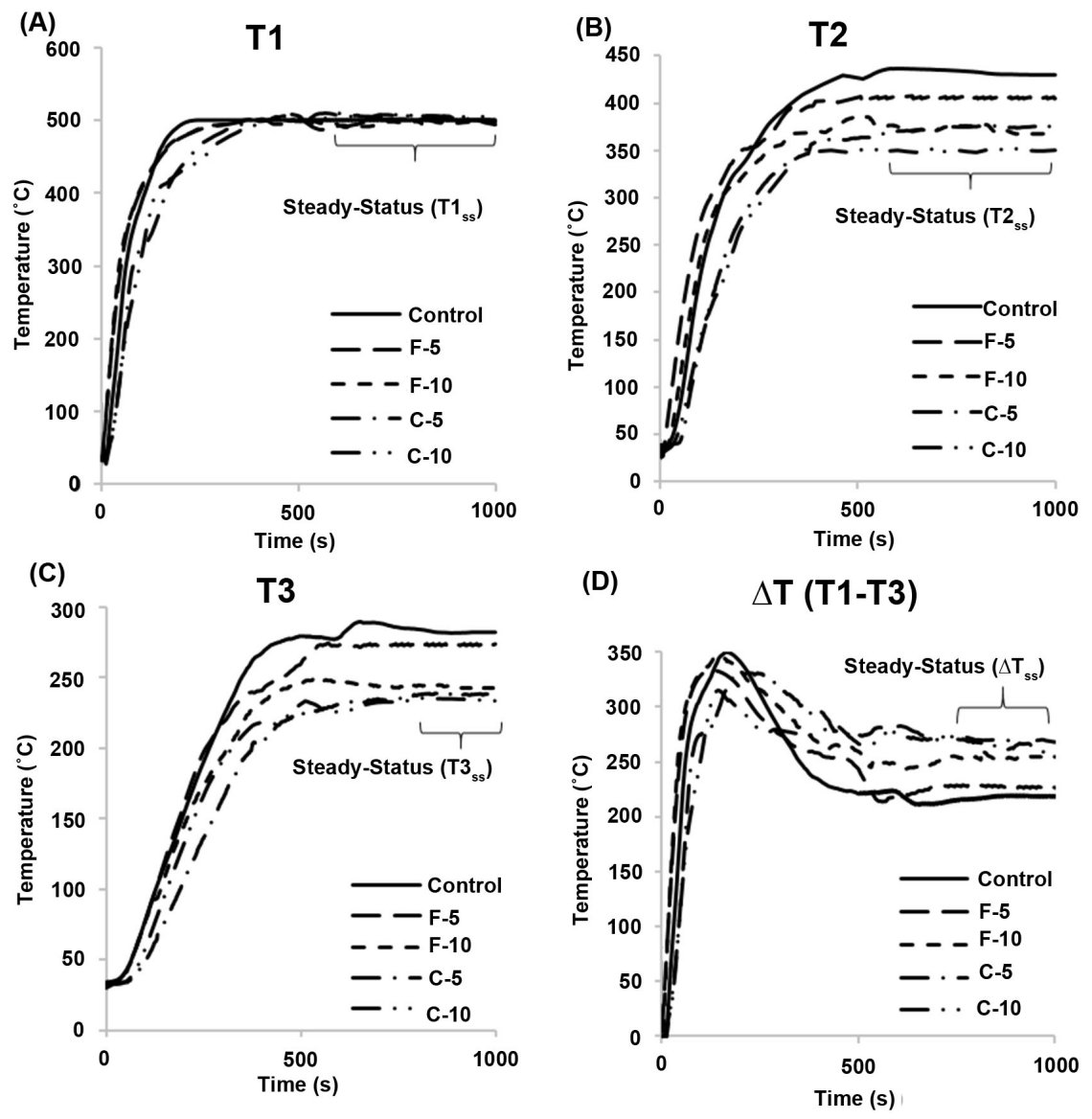

Figure 6. the temperature-time profiles at the (T1) the front surface of sandwich exposed to flame, (T2) the honeycomb of sandwich, (T3) the back skin of the sandwich.

was shown to decrease from $\mathbb{2} 85^{\circ} \mathrm{C}$ (Control) to $₫ 70^{\circ} \mathrm{C}(\mathrm{F}-5)$ and $₫ 43^{\circ} \mathrm{C}(\mathrm{F}-10)$ with the addition of EG. Different from F-Composites, the fire-proof approach of C-Composites was using the EG on the face sheet to form dense char layer exposed to fire. Compared to Control, the $\mathrm{T} 2_{\mathrm{SS}}$ of C-Composite was decreased from $\$ 00^{\circ} \mathrm{C}$ to $\varangle 74^{\circ} \mathrm{C}(\mathrm{C}-5)$ and $\$ 50^{\circ} \mathrm{C}(\mathrm{C}-10)$, respectively. In addition, the $\mathrm{T} 3_{\text {ss }}$ of C-Composite was decreased from $₫ 85^{\circ} \mathrm{C}$ to $₫ 239^{\circ} \mathrm{C}(\mathrm{C}-5)$, and $₫ 35^{\circ} \mathrm{C}$ (C-10). With the comparison between $\mathrm{T} 1$ and $\mathrm{T} 3$, the $\Delta \mathrm{T}$ of all composite could be calculated to indicate the thermal insulation performance of sandwich with EG. According to Figure 6 and Figure 7, with an increase of EG from 0 to $10 \mathrm{wt} \%, \Delta \mathrm{T}$ for F-Composite was increased from $\$ 18^{\circ} \mathrm{C}$ (Control) to $\$ 27^{\circ} \mathrm{C}(\mathrm{F}-5)$ and $\bowtie 54^{\circ} \mathrm{C}$ (F-10), whilst that for C-Composite was increased to $₫ 55^{\circ} \mathrm{C}$ (C-5) and $\$ 69^{\circ} \mathrm{C}(\mathrm{C}-10)$.

Therefore, the EG filled into the core-honeycomb and coated on the face sheet of the sandwich were available approaches to improve the flame retardancy and thermal insulation of sandwich composite. For the same mass fraction of EG addition, the composite with EG coating presented shorter burning length, lower PHRR value and MAHRE value, higher $\triangle \mathrm{T}$ value, when compared to composite filled with EG. However, the more smoke released with EG coating should be 

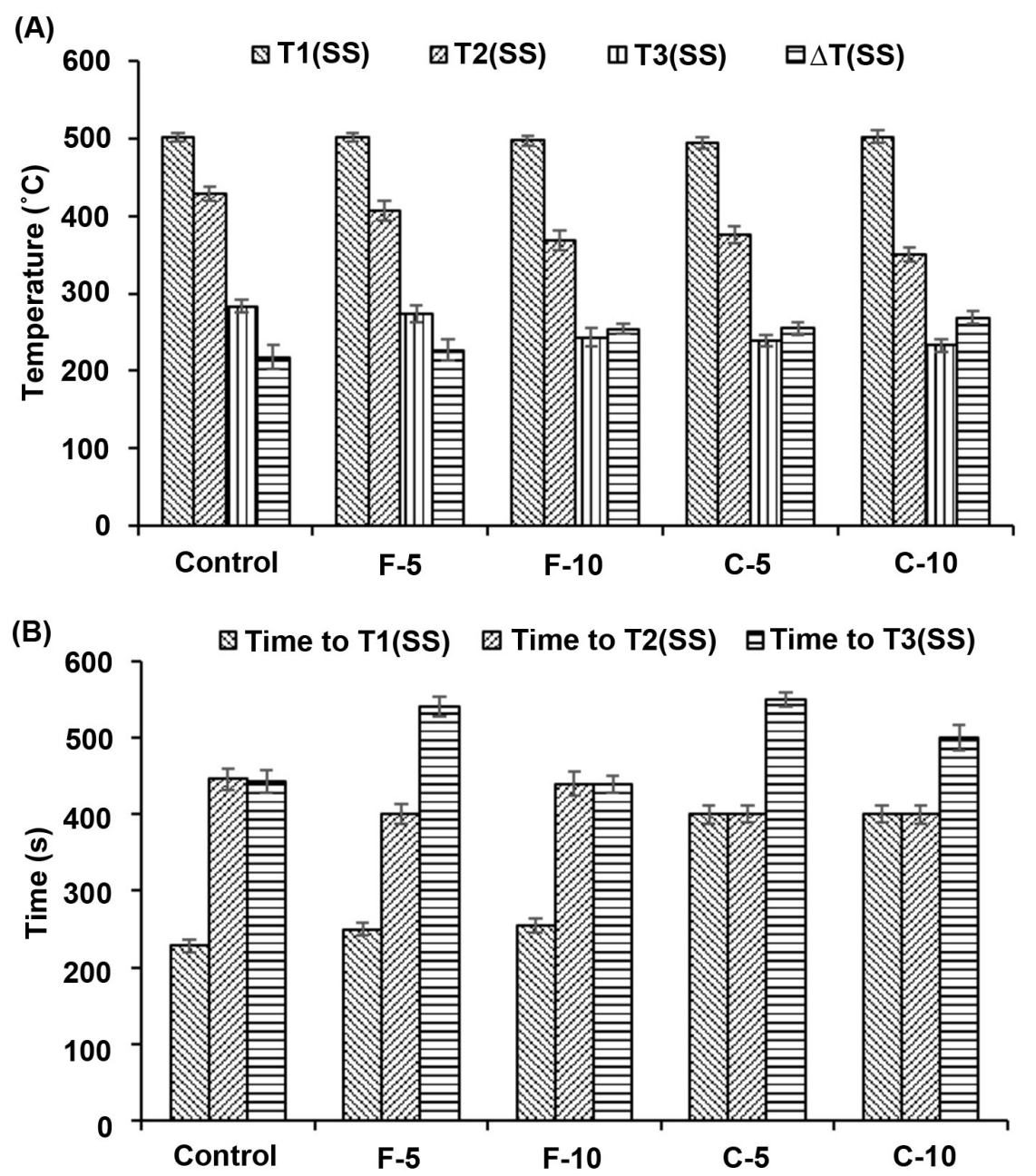

Figure 7. The thermal equilibrium temperature (A) of specimens and the time (B) to the thermal equilibrium temperature.

considered during the application, so that the coordination with other flame retardant agent for EG coating could be a good approach to improve the fire retardant performance.

\subsection{Mechanical Test}

The effect of EG on the mechanical composite has been illustrated in literature, whilst the most of them were focused on the laminate composite with the EG mixed in the resin. As such, the effect of EG on the sandwich composite should be analysed and the mechanical performance of novel structure sandwich where the EG was filled in the honeycomb core or coated on the laminate skin could be compared. The Load-displacement curves of the specimens during the three-point bending test was shown in Figure 8. The sandwich structure with EG filled and coated had presented similar failure behaviour when compared to Control. As such, no significant difference was observed amongst the maximum load and the core shear failure of specimens with EG and Control. However, the sandwich with EG filled and coated was easier delaminated and failed with 


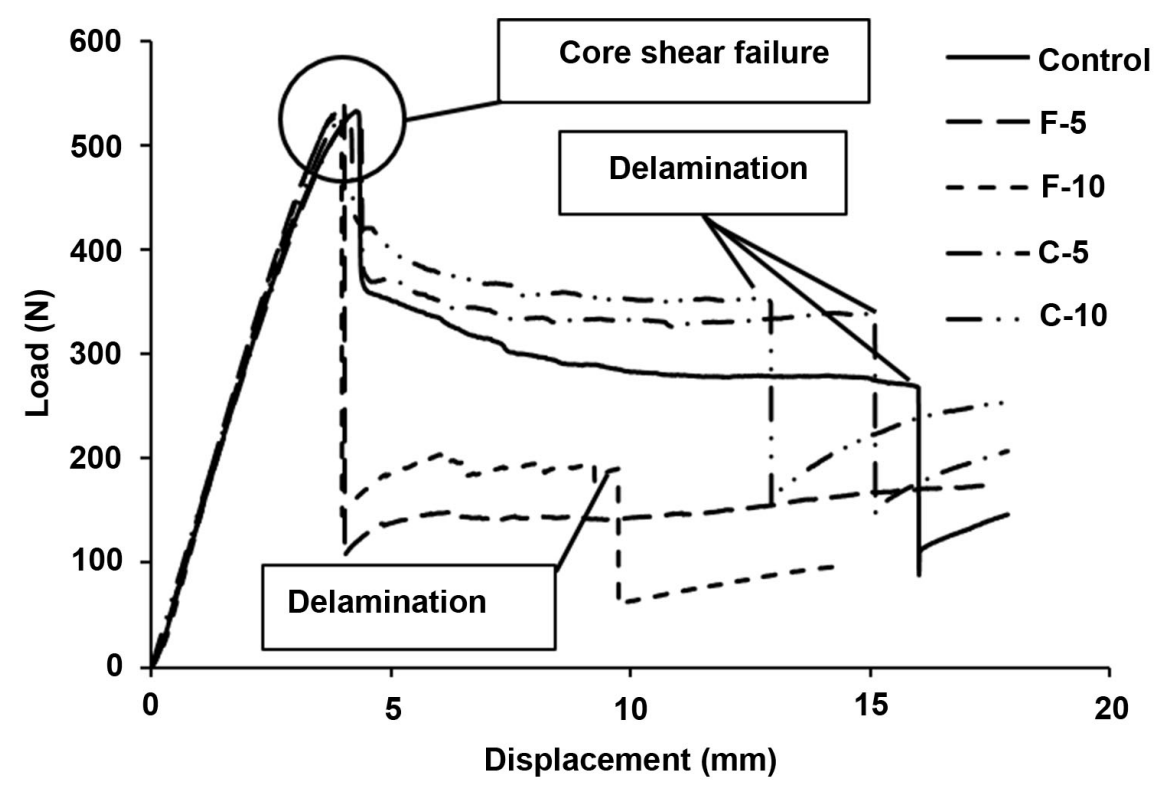

Figure 8. Flexural load-Displacement curve of sandwich composite.

core-to-face disband in the bending test. According to Figure 9, there is no significant difference figured out from the Core Shear Ultimate Strength ( $\left.F_{s}^{\text {ult }}\right)$ and Face Stress around the sandwich structure with EG (F-5, F-10, C-5, C-10) and Control. This was confirmed that the sandwich structure was not influenced by the EG filled in the honeycomb or coated on the face sheet.

\section{Conclusions}

In this study, the sandwich composite was developed using carbon fibre reinforced composite and honeycomb. The expandable graphite (EG) was used to fill in the honeycomb of sandwich or coat on the face sheet of the sandwich to improve the fire-proofing performance.

According to the results, the burn length of the composite with the addition of EG in the vertical burning test was reduced significantly when compared to the control. With the addition of $10 \mathrm{wt} \% \mathrm{EG}$, the PHRR values were reduced from 322 to $103 \mathrm{KW} / \mathrm{m}^{2}$ for C-Composite and $155 \mathrm{KW} / \mathrm{m}^{2}$ for F-Composite. Additionally, the value of THR and MAHRE observed for F-Composite was reduced by $37 \%$ and $36 \%$, whilst the decrease of C-Composite was $74 \%$ and $68 \%$, respectively. However, the TSR value for F-Composite was observed to decrease by $43 \%$, whilst that for C-Composite was increased by $35 \%$. For thermal insulation performance of sandwich, C-Composite presented higher temperature difference between two face sheets than F-Composite with the same mass fraction of EG added. For mechanical properties analysis, no significant effect on the flexural properties could be figured out due to no influence on the interface and structure.

Therefore, the sandwich composite with EG coated or filled showed significant improvement on flame retardant performance and thermal insulation properties 


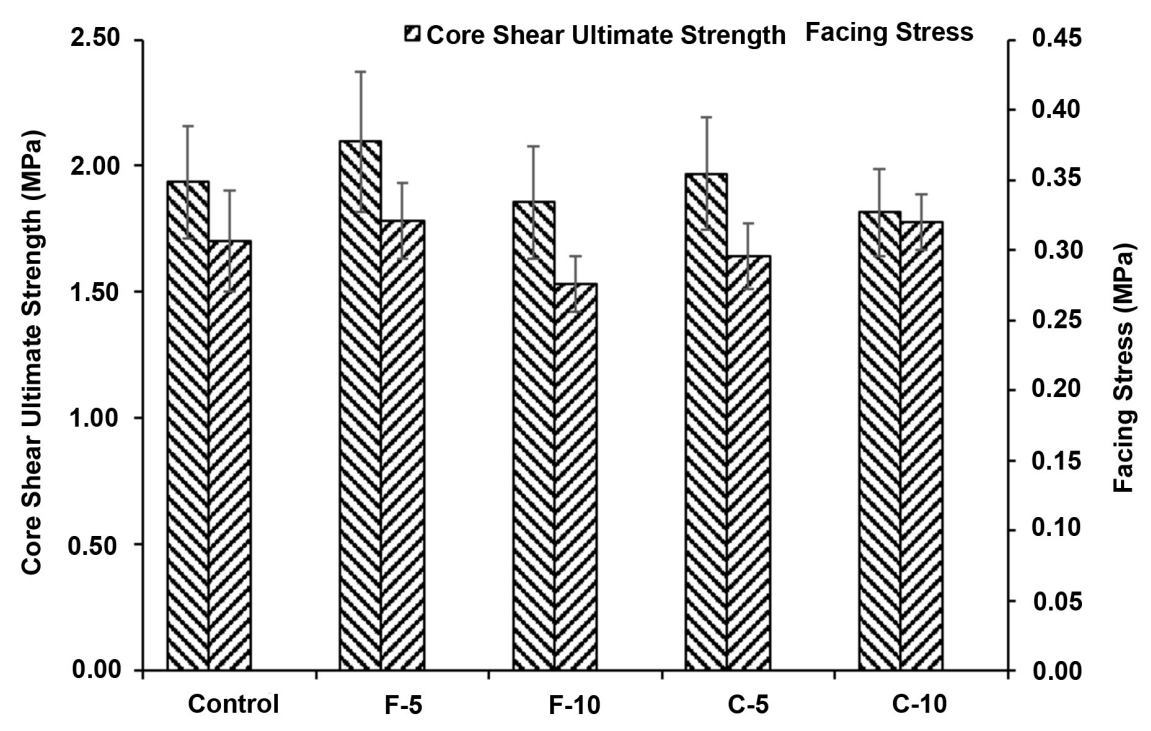

Figure 9. The Core Shear Ultimate Strength and Facing Stress of sandwich structures.

of sandwich composite. However, for comparison, the approach of EG coating could present better flame retardant performance with much lower PHRR and MAHRE, whereas the more smoke released should be taken into account in future study. For future application of sandwich composite on the flame retardant area, the EG coating could be a good approach for flameproof, but the smoke generation should be compressed via the addition of flame retardant agent for coordination.

\section{Acknowledgements}

This work was carried out in ACC-UNNC Joint Laboratory in Sustainable Composite Materials. Authors would like to appreciate the financial supported by Ningbo 3315 Innovation team Scheme "Marine Composites Development and Manufacturing for Sustainable Environment", Ningbo High-Tech Zone "New Carbon Fibre Composite Technologies and Materials in Aerospace Functional Application", and Zhejiang Innovation Team "Multi-functional green composite for the next generation aerospace application".

\section{Conflicts of Interest}

The authors wish to confirm that there are no known conflicts of interest associated with this publication.

\section{References}

[1] Gibson, R.F. (2011) Principles of Composite Material Mechanics. 3rd Edition, Taylor \& Francis, Abingdon.

[2] Wakeman, M.D., Cain, T.A., Rudd, C.D., Brooks, R. and Long, A.C. (1999) Compression Moulding of Glass and Polypropylene Composites for Optimised Macroand Micro- Mechanical Properties 3. Sandwich Structures of GMTS and Commingled Fabrics. Composites Science and Technology, 59, 1153-1167. 
https://doi.org/10.1016/S0266-3538(98)00155-9

[3] Constantin, N., Sandu, M., Sandu, A. and Găvan, M. (2017) Damage Identification and Mechanical Assessment of Impacted Sandwich Composites. Procedia Engineering, 188, 178-185. https://doi.org/10.1016/j.proeng.2017.04.472

[4] Hörold, A., Schartel, B., Trappe, V., Korzen, M. and Bünker, J. (2017) Fire Stability of Glass-Fibre Sandwich Panels: The Influence of Core Materials and Flame Retardants. Composite Structures, 160, 1310-1318.

https://doi.org/10.1016/j.compstruct.2016.11.027

[5] Vitale, J.P., Francucci, G. and Stocchi, A. (2017) Thermal Conductivity of Sandwich Panels Made with Synthetic and Vegetable Fiber Vacuum-Infused Honeycomb Cores. Journal of Sandwich Structures \& Materials, 19, 66-82. https://doi.org/10.1177/1099636216635630

[6] Kim, M. and Choe, J. (2016) Development of the Fire-Retardant Sandwich Structure Using an Aramid/Glass Hybrid Composite and a Phenolic Foam-Filled Honeycomb. Composite Structures, 158, 227-234. https://doi.org/10.1016/j.compstruct.2016.09.029

[7] Anjang, A., Chevali, V., Lattimer, B., Case, S., Feih, S. and Mouritz, A. (2015) Post-Fire Mechanical Properties of Sandwich Composite Structures. Composite Structures, 132, 1019-1028. https://doi.org/10.1016/j.compstruct.2015.07.009

[8] Laoutid, F., Bonnaud, L., Alexandre, M., Lopez-Cuesta, J.-M. and Dubois, P. (2009) New Prospects in Flame Retardant Polymer Materials: from Fundamentals to Nanocomposites. Materials Science and Engineering: R: Reports, 63, 100-125. https://doi.org/10.1016/j.mser.2008.09.002

[9] Rakotomalala, M., Wagner, S. and Döring, M. (2010) Recent Developments in Halogen Free Flame Retardants for Epoxy Resins for Electrical and Electronic Applications. Materials, 3, 4300-4327. https://doi.org/10.3390/ma3084300

[10] Weil, E.D. (2011) Fire-Protective and Flame-Retardant Coatings-A State-of-theArt Review. Journal of Fire Sciences, 29, 259-296. https://doi.org/10.1177/0734904110395469

[11] Bar, M., Alagirusamy, R. and Das, A. (2015) Flame Retardant Polymer Composites. Fibers and Polymers, 16, 705-717. https://doi.org/10.1007/s12221-015-0705-6

[12] Kandare, E., Kandola, B.K., McCarthy, E.D., Myler, P., Edwards, G., Jifeng, Y. and Wang, Y.C. (2011) Fiber-Reinforced Epoxy Composites Exposed to High Temperature Environments. Part II: Modeling Mechanical Property Degradation. Journal of Composite Materials, 45, 1511-1521. https://doi.org/10.1177/0021998310385024

[13] Kandare, E., Kandola, B.K., Myler, P. and Edwards, G. (2010) Thermo-Mechanical Responses of Fiber-Reinforced Epoxy Composites Exposed to High Temperature Environments. Part I: Experimental Data Acquisition. Journal of Composite Materials, 44, 3093-3114. https://doi.org/10.1177/0021998310373511

[14] Wu, T.-C., Tsai, K.-C., Lu, M.-C., Kuan, H.-C., Chen, C.-H., Kuan, C.-F., Chiu, S.-L., Hsu, S.-W. and Chiang, C.-L. (2012) Synthesis, Characterization, and Properties of Silane-Functionalized Expandable Graphite Composites. Journal of Composite Materials, 46, 1483-1496. https://doi.org/10.1177/0021998310373511

[15] Focke, W.W., Badenhorst, H., Mhike, W., Kruger, H.J. and Lombaard, D. (2014) Characterization of Commercial Expandable Graphite Fire Retardants. Thermochimica Acta, 584, 8-16. https://doi.org/10.1016/j.tca.2014.03.021

[16] Focke, W.W., Muiambo, H., Mhike, W., Kruger, H.J. and Ofosu, O. (2014) Flexible PVC Flame Retarded with Expandable Graphite. Polymer Degradation and Stabil- 
ity, 100, 63-69. https://doi.org/10.1016/j.polymdegradstab.2013.12.024

[17] Camino, G., Duquesne, S., Delobel, R., Eling, B., Lindsay, C. and Roels, T. (1974) Polyurethanes-8 Mechanism of Expandable Graphite Fire Retardant Action in Polyurethanes. ACS Symposium Series, American Chemical Society, Washington DC.

[18] Chung, D. (2016) A Review of Exfoliated Graphite. Journal of Materials Science, 51, 554-568. https://doi.org/10.1007/s10853-015-9284-6

[19] Khalili, P., Tshai, K. and Kong, I. (2017) Natural Fiber Reinforced Expandable Graphite Filled Composites: Evaluation of the Flame Retardancy, Thermal and Mechanical Performances. Composites Part A: Applied Science and Manufacturing, 100, 194-205. https://doi.org/10.1016/j.compositesa.2017.05.015

[20] Mngomezulu, M.E., Luyt, A.S., Chapple, S.A. and John, M.J. (2018) Effect of Expandable Graphite on Thermal and Flammability Properties of Poly(Lactic Acid)-Starch/Poly( $\varepsilon$-Caprolactone) Blend Systems. Polymer Engineering \& Science, 58, 1619-1629. https://doi.org/10.1002/pen.24751

[21] Cheng, J.-J. and Zhou, F.-B. (2016) Influence of Expandable Graphite on Flame Retardancy and Mechanical Properties of Organic-Inorganic Hybrid Material Based on Sodium Silicate and Polyisocyanate. Journal of Thermal Analysis and Calorimetry, 126, 1417-1426. https://doi.org/10.1007/s10973-016-5621-5

[22] Wang, N., Xu, G., Wu, Y., Zhang, J., Hu, L., Luan, H. and Fang, Q. (2016) The Influence of Expandable Graphite on Double-Layered Microcapsules in Intumescent Flame-Retardant Natural Rubber Composites. Journal of Thermal Analysis and Calorimetry, 123, 1239-1251. https://doi.org/10.1007/s10973-015-5011-4

[23] Yang, S., Wang, J., Huo, S., Wang, M., Wang, J. and Zhang, B. (2016) Synergistic Flame-Retardant Effect of Expandable Graphite and Phosphorus-Containing Compounds for Epoxy Resin: Strong Bonding of Different Carbon Residues. Polymer Degradation and Stability, 128, 89-98.

https://doi.org/10.1016/j.polymdegradstab.2016.03.017 